\title{
Active HCV Replication but Not HCV or CMV Seropositive Status Is Associated With Incident and Prevalent Type 2 Diabetes in Persons Living With HIV
}

\author{
Andrea De Luca, MD, *† Patrizia Lorenzini, BSc, $\neq$ Antonella Castagna, MD, $\S$ Massimo Puoti, MD, $\|$ \\ Nicola Gianotti, MD, \& Francesco Castelli, MD, PhD, $q$ Claudio Mastroianni, MD,\# \\ Franco Maggiolo, MD,** Andrea Antinori, MD, †† Giovanni Guaraldi, MD, $\neq \neq$ \\ Miriam Lichtner, MD, PhD, $\S \S$ and Antonella d'Arminio Monforte, MD, \|\| \\ for the ICONA Foundation Study
}

\begin{abstract}
Objective: To analyze the association between chronic hepatitis $\mathrm{C}$ virus (HCV) and cytomegalovirus (CMV) infections with type 2 diabetes in HIV-infected patients.
\end{abstract}

Methods: HIV-1-infected patients enrolled in ICONA, a prospective cohort study involving 42 tertiary care centers in Italy, were

Received for publication August 14, 2016; accepted April 17, 2017.

From the *Dipartimento di Biotecnologie Mediche, Università degli Studi di Siena; $\dagger$ †OC Malattie Infettive Universitarie ed Epatologia, Dipartimento di Medicina Interna e Specialistica, Azienda Ospedaliera Universitaria Senese, Siena, Italy; \$National Institute for Infectious Diseases "L Spallanzani, Roma, Italy; $\S$ Division of Infectious Diseases, Hospital San Raffaele, Milan, Italy; ||Division of Infectious Diseases, Niguarda Hospital, Milan, Italy; Department of Infectious Diseases, University of Brescia, Brescia, Italy; \#Division of Infectious Diseases, AO Giovanni XXIII, Bergamo, Italy; **Division of Infectious Diseases, University La Sapienza, Polo Pontino, Latina, Italy; ††INMI "L Spallanzani," Rome, Italy; †tDivision of Infectious Diseases, University of Modena and Reggio Emilia, Modena, Italy; $\S$ Division of Infectious Diseases, University La Sapienza, Polo Pontino, Latina, Italy; and \|\| Division of Infectious Diseases, University of Milan, San Paolo Hospital, Milan, Italy.

ICONA Foundation received unrestricted grants from Abbvie, BMS; Gilead, Janssen, MSD and ViiV Italy.

Preliminary findings of this analysis have been presented at the EACS Conference, Barcelona, Spain, October 21-24, 2015, abstract PE15/80.

A.D.L. was a member of advisory boards or a paid consultant for ViiV Healthcare, Gilead Sciences, Abbvie, Bristol-Myers Squibb, Janssen, Merck; A.C. was a consultant for ViiV Healthcare, Gilead Sciences, Abbvie, Bristol-Myers Squibb, Janssen, Merck; M.P. was a consultant for Gilead Sciences, Abbvie, Bristol-Myers Squibb, Janssen and Merck; N.G. was a consultant for ViiV Healthcare, Gilead Sciences, Abbvie, BristolMyers Squibb, Janssen, Merck; C.M. was member of advisory board or a paid consultant for ViiV Healthcare, Gilead Sciences, Abbvie, BristolMyers Squibb, Janssen, Merck; F.M. was a paid consultant or member of advisory boards for ViiV Healthcare, Gilead Sciences, Abbvie, BristolMyers Squibb, Janssen, Merck; A.A. was a paid consultant or member of advisory boards for ViiV Healthcare, Gilead Sciences, Abbvie, BristolMyers Squibb, Janssen, Merck; G.G. was a paid consultant or member of advisory boards for ViiV Healthcare, Gilead Sciences, Abbvie, BristolMyers Squibb, Janssen, Merck; A.d'M.A. was a paid consultant or member of advisory boards for ViiV Healthcare, Gilead Sciences, Abbvie, Bristol-Myers Squibb, Janssen, Merck; The remaining authors have no conflict of interests to disclose.

Members of the ICONA Foundation Study are listed in the Acknowledgements.

Correspondence to: Andrea De Luca, MD, UOC Malattie Infettive Universitarie e Malattie Infettive ed Epatologia, AOU Senese, Viale M Bracci 16_53100 Siena, Italy (e-mail: andrea.deluca@unisi.it).

Copyright (C) 2017 Wolters Kluwer Health, Inc. All rights reserved. selected with the following characteristics: for the diabetes incidence analysis, all patients with available CMV IgG results (first available test = baseline) and without type 2 diabetes were followed until onset of type 2 diabetes, last available clinical follow-up, death or September 30, 2014, whichever occurred first; for the prevalence analysis, all ICONA patients were analyzed at their last follow-up visit. Main outcome measures were the new onset of type 2 diabetes (incidence analysis) and the prevalence of type 2 diabetes at last follow-up.

Results: During 38,062 person-years of follow-up (PYFU) in 6505 individuals, we observed 140 cases of incident type 2 diabetes (Incidence rate $3.7,95 \% \mathrm{CI}: 3.1$ to 4.3 , per $1000 \mathrm{PYFU}$ ). In a multivariable Poisson regression model, HCV-antibody (Ab) +/HCV RNA+ patients [adjusted relative rate versus HCV-Ab negative 1.73 (95\% CI: 1.08 to 2.78)] but not HCV Ab+RNA - or CMV IgG+ patients, had a higher risk of diabetes. Among 12,001 patients, 306 (2.5\%) prevalent cases of type 2 diabetes were detected. HCV Ab +RNA+ status was independently associated with prevalent diabetes (adjusted Odds Ratio vs HCV Ab- 2.49; 95\% CI: 1.08 to 5.74), whereas $\mathrm{HCV}-\mathrm{Ab}+/ \mathrm{HCV}$ RNA - and $\mathrm{CMV} \mathrm{IgG+} \mathrm{status} \mathrm{were} \mathrm{not.}$

Conclusion: In HIV-infected individuals, active HCV replication but not prior $\mathrm{HCV}$ exposure or latent $\mathrm{CMV}$ infection is associated with incident and prevalent type 2 diabetes.

Key Words: HIV-1, HCV, diabetes, HCV-RNA, CMV

(J Acquir Immune Defic Syndr 2017;75:465-471)

\section{INTRODUCTION}

Antiretroviral therapy has significantly reduced HIVassociated morbidity and mortality. ${ }^{1}$ However, the substantially increased survival has exposed the HIV-infected population to a relevant number of co-morbid conditions, such as metabolic and cardiovascular disorders, ${ }^{2}$ and to the long-term consequences of chronic co-infections, including chronic hepatitis $\mathrm{C}$ virus $(\mathrm{HCV})$ infection. ${ }^{3}$ Among the metabolic disorders, type 2 diabetes affects a relevant number of persons living with HIV. Although diabetes mellitus does not seem more frequent in HIV-infected subjects than in negative controls, ${ }^{4}$ in the HIV-infected population diabetes represents a risk factor for all specific causes of death except 
non-AIDS cancers. ${ }^{5}$ Moreover, exposure to some antiretroviral agents may also favor the emergence of type 2 diabetes. $^{6-8}$ In any case, the clinical impact of diabetes, as a risk factor for cardiovascular and cerebrovascular disorders, may be more relevant in the HIV-infected population where the incidence of cardiovascular disease is already increased as compared to the age-matched general population. ${ }^{2}$

Chronic viral infections lead to immune activation and may therefore cause a number of co-morbidities. Indeed, chronic HCV infection, apart from causing liver-related morbidity and mortality, is also associated with an increased incidence of extra-hepatic disorders, including diabetes and cardiovascular disease, in the HIV-negative population. ${ }^{9,10}$

In HCV-infected patients, HIV co-infection has been associated with an accelerated liver disease. ${ }^{3}$ Whether HCV co-infection favors the emergence of diabetes in HIV-infected patients remains to be fully established. Some reports indicate a similar incidence of type 2 diabetes in HCV-antibodypositive HIV-infected patients ${ }^{11,12}$ while other studies indicate that $\mathrm{HCV}$-antibody-positive individuals have an increased risk. ${ }^{4,10}$ However, it is not clear whether $\mathrm{HCV}$ antibody positivity is a marker for a specific population exposed to a higher risk of diabetes due to behavioral factors or whether HCV infection by itself represents a risk factor for this disorder. In addition, latent cytomegalovirus (CMV) infection, as determined by a positive CMV-antibody serostatus, has been associated with an increased incidence of nonAIDS events, particularly cardiovascular events, ${ }^{13}$ because of an immune activation mechanism. Latent CMV infection has also been associated with diabetes mellitus. ${ }^{14}$

Aim of our study was to determine the impact of HCV infection, both as prior $\mathrm{HCV}$ exposure and as active $\mathrm{HCV}$ infection, and of latent CMV infection on the incidence and the prevalence of type 2 diabetes in a nationally representative Italian cohort of HIV-infected individuals.

\section{PATIENTS AND METHODS}

Patient selection for the incidence and prevalence analysis and definition of type 2 diabetes.

For the incident type 2 diabetes analysis, patients enrolled in the ICONA Foundation Study cohort ${ }^{15}$ were selected who (1) had an available CMV IgG result (time of first result $=$ baseline) and (2) did not have diabetes at baseline. For the prevalent type 2 diabetes analysis, all ICONA enrollees were evaluated at the date of diabetes diagnosis or at their last available follow-up, whichever occurred first. Type 2 diabetes was defined by one of the following criteria: (1) diagnosis by the treating clinician, (2) use of antidiabetic drugs, or (3) first of 2 consecutive blood glucose levels $>125 \mathrm{mg} / \mathrm{dL}$ at a verified fasting status. All the type 2 diabetes diagnoses were validated by an external monitor using the above criteria.

\section{Statistical Analysis}

We used standard descriptive statistics to describe characteristics at baseline for the population analyzed for the diabetes incidence and at the date of diabetes diagnosis or last available follow-up for the population analyzed for the diabetes prevalence. Time to diagnosis of diabetes was analyzed using the Kaplan-Meier method using the time of first CMV serology as baseline. Patients were followed until onset of type 2 diabetes, last available clinical follow-up, death or September 30, 2014, whichever occurred first. Predictors of incident type 2 diabetes were analyzed by Poisson regression. In the multivariable model, we included variables with $P<0.10$ at univariate analysis plus CMV serostatus. The type of antiretroviral treatment regimen used was analyzed as time updated variable.

Factors associated with prevalent type 2 diabetes at the last available follow-up were analyzed by logistic regression; multivariable models included variables with $P<0.10$ at univariate analysis.

\section{RESULTS}

\section{Incidence Analysis}

Six thousand five hundred five patients were suitable for the type 2 diabetes incidence analysis. Baseline patients characteristics are summarized in Table 1 (left part).

CMV IgG were detected in $84.4 \%$ of 6,505 , HCVantibodies in $31.5 \%$ of 6112 tested, of whom $83.5 \%$ of 1033 tested had a detectable HCV RNA. During 38.062 personyears of follow-up (PYFU), we observed 140 cases of incident type 2 diabetes with an incidence rate of 3.7 (95\% CI: 3.1 to 4.3) per 1.000 PYFU. Time-to-event analysis showed that the 5-years, 10-years, and 15-years estimated probability of type 2 diabetes were $1.8 \%$ (95\% CI: 1.5 to 2.3$), 3.4 \%(2.8-4.1)$ and 5.4\% (4.4-6.7), respectively (Fig. 1). By multivariable Poisson regression analysis (Table 2), HCV RNA-positive status, but not HCV-antibody positive, HCV RNA negative status was independently associated with a higher incidence of type 2 diabetes as compared to an HCV-antibody negative status [adjusted relative rate, ARR, 1.73 (1.08-2.78)]; CMV IgG serology was not associated with incident diabetes. Other independent predictors of diabetes onset were male gender, older age, a higher baseline BMI, higher baseline glucose and triglycerides levels, presence of arterial hypertension, current use of a regimen containing NRTIs with an unboosted protease inhibitor (as compared with NRTI with NNRTI), and current use of stavudine+lamivudine as compared to tenofovir + emtricitabine (Table 2).

\section{Prevalence Analysis}

Prevalent type 2 diabetes analysis was performed on 12,001 patients at their last follow-up in ICONA. Characteristics of the patients used in the prevalence analysis are summarized in Table 1 (right side). HCV antibodies were detected in $29.3 \%$ of 10,611 tested, whereas HCV RNA was detectable in $75.1 \%$ of 1095 tested; CMV IgG were positive in $84.6 \%$ of 7033 tested. Three hundred six patients $(2.5 \%)$ had a diagnosis of type 2 diabetes at last follow-up. Factors associated with prevalent diabetes are summarized in Table 3. Again, HCV RNA-positive status [adjusted odds ratio, AOR $2.49(1.08-5.74)]$ was independently associated with prevalent type 2 diabetes, whereas HCV-antibody-positive, $\mathrm{HCV}$ 
TABLE 1. Characteristics of Study Patients

\begin{tabular}{|c|c|c|c|c|}
\hline \multirow{2}{*}{$\begin{array}{l}\text { Characteristic } \\
\text { Calendar month median (IQR) }\end{array}$} & \multicolumn{2}{|c|}{$\begin{array}{c}\text { Baseline Characteristics of } \\
\text { Patients Used in the Incidence } \\
\text { Analysis }(n=6505)\end{array}$} & \multicolumn{2}{|c|}{$\begin{array}{c}\text { Characteristics of Patients } \\
\text { at the Time of the Prevalence } \\
\text { Analysis }(n=12,001)\end{array}$} \\
\hline & June 2002 & January 1998-April 2010 & March 2003 & July 1999-June 2009 \\
\hline Age, median (IQR), yr & 36 & $31-42$ & 41 & $35-49$ \\
\hline \multicolumn{5}{|l|}{ Mode of HIV transmission, $\mathrm{n}(\%)$} \\
\hline Heterosexual contacts & 2624 & 40.3 & 4581 & 38.2 \\
\hline Other/unknown & 363 & 5.6 & 806 & 6.7 \\
\hline CDC stage $\mathrm{C}, \mathrm{n}(\%)$ & 706 & 10.8 & 1681 & 14.1 \\
\hline \multicolumn{5}{|l|}{ BMI category, $\mathrm{kg} / \mathrm{m}^{2}, \mathrm{n}(\%)$} \\
\hline$<18$ & 304 & 4.7 & 351 & 2.9 \\
\hline $18.5-25.9$ & 3765 & 57.9 & 4609 & 38.4 \\
\hline AST median (IQR), IU/mL & 27 & $20-42$ & 25 & $19-37$ \\
\hline Creatinine median (IQR), mg/dL & 0.9 & $0.7-1.0$ & 0.9 & $0.7-1.0$ \\
\hline Triglycerides median (IQR), mg/dL & 109 & $77-157$ & 115 & $81-172$ \\
\hline Total cholesterol median (IQR), mg/dL & 165 & $138-193$ & 179 & $150-210$ \\
\hline Hypertension, n (\%) & 1116 & 17.2 & 2540 & 21.2 \\
\hline CD4 nadir, median (IQR), cells $/ \mu \mathrm{L}$ & 380 & $192-569$ & 238 & $147-420$ \\
\hline \multicolumn{5}{|l|}{$\mathrm{CD} 4$ nadir, $\mathrm{n}(\%)$ in category of cells $/ \mu \mathrm{L}$} \\
\hline $0-199, \mathrm{n}(\%)$ & 1548 & 23.8 & 3763 & 31.4 \\
\hline $200-349$, n (\%) & 1187 & 18.2 & 3458 & 28.8 \\
\hline $350+, \mathrm{n}(\%)$ & 3271 & 50.3 & 4131 & 34.4 \\
\hline Missing & 499 & 7.7 & 645 & 5.4 \\
\hline 2 & 25 & 2.9 & 11 & 1.3 \\
\hline 3 & 263 & 30.5 & 115 & 14.0 \\
\hline 4 & 90 & 10.4 & 52 & 6.3 \\
\hline Mixed/unknown & 129 & 14.9 & 447 & 54.4 \\
\hline HCV RNA load, median (IQR) $\log _{10} I U / m L$ & 5.9 & $5.4-6.3$ & 5.9 & $5.5-6.4$ \\
\hline \multicolumn{5}{|l|}{ HBsAg } \\
\hline Positive & 330 & 5.1 & 554 & 4.6 \\
\hline Negative & 6009 & 92.4 & 9827 & 81.9 \\
\hline Not known & 166 & 2.5 & 1620 & 13.5 \\
\hline \multicolumn{5}{|l|}{ CMV IgG } \\
\hline Positive & 5488 & 84.4 & 1085 & 9.0 \\
\hline Negative & 1017 & 15.6 & 5948 & 49.6 \\
\hline Not known & 0 & 0 & 4968 & 41.4 \\
\hline $\begin{array}{l}\text { Patients initiating ART (Incidence analysis) or on ART } \\
\text { (prevalence analysis) }\end{array}$ & 5442 & 83.7 & 7451 & 62.1 \\
\hline
\end{tabular}

*Among the HCV RNA positives.

ART, antiretroviral therapy; BMI, body mass index; CDC, centers for disease control; CMV, Cytomegalovirus; IDU, injecting drug users; MSM, men having sex with men; NNRTI, non-nucleoside reverse transcriptase inhibitors; NRTI, nucleoside reverse transcriptase inhibitors; PI, protease inhibitors. 


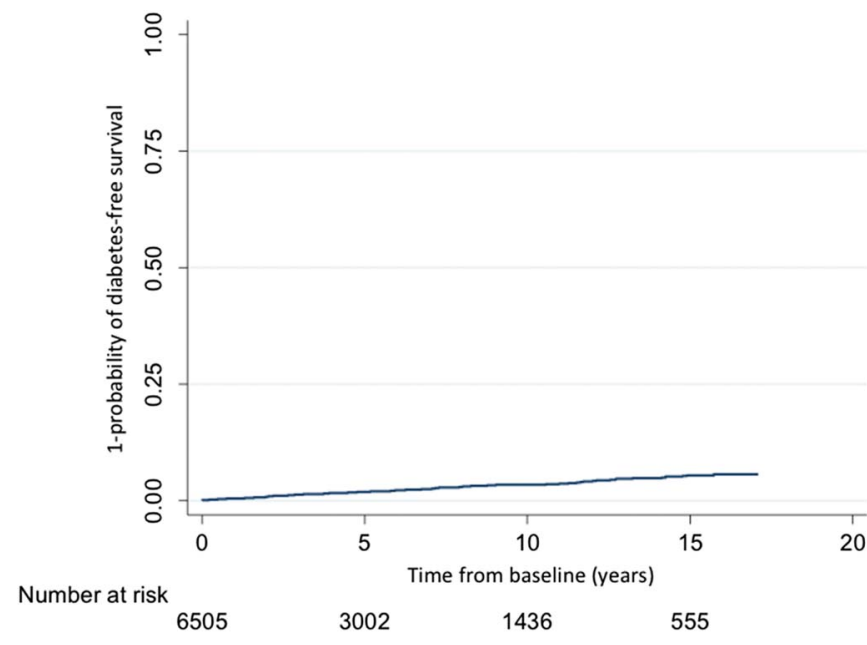

FIGURE 1. Estimated probability of type 2 diabetes. KaplanMeier method. Baseline was the time of the first available CMV serology. Patients with pre-baseline diabetes were excluded.

RNA-negative status was not. Also, in this analysis, CMV IgG serology was not associated with diabetes. Other factors independently associated with prevalent diabetes were older age, a more recent time from HIV diagnosis, higher BMI, and current use of zidovudine + lamivudine, didanosine + stavudine, didanosine + lamivudine or other (uncommon) NRTI combinations as compared to tenofovir + emtricitabine. Interestingly, transaminase levels were associated with prevalent diabetes at univariate analysis but lost this association in the adjusted model completely.

\section{DISCUSSION}

In this cohort study, we observed how, in HIV-infected patients, active HCV replication was independently associated both with incident and prevalent type 2 diabetes. Interestingly, this association was not observed in HCVseropositive individuals without active HCV replication. This association was independent from several confounders including ALT or AST in both incident and prevalent diabetes analysis.

Our findings contribute to resolve the contradictory observations made in the HIV-positive and HIV-negative population, where the association between $\mathrm{HCV}$ and diabetes was mostly studied using $\mathrm{HCV}$ antibody status as marker of $\mathrm{HCV}$ infection. Indeed, an association was observed in some studies $^{4,10}$ but not confirmed in others. ${ }^{11,12}$ In the HIVinfected population, approximately $80 \%-85 \%$ of $\mathrm{HCV}$ antibody-positive patients show a detectable serum HCV RNA. The proportion of HCV-antibody-positive patients without active HCV replication is deemed to increase because of the spread of highly effective $\mathrm{HCV}$ eradication therapies with direct acting antivirals. ${ }^{16}$ Given the observed association with active HCV replication but not with simple HCVantibody-positive status, our study reinforces the hypothesis that HCV infection and replication per se and not its associated behavioral or biological factors are directly involved in the pathogenesis of type 2 diabetes.
Several biological mechanisms have been hypothesized through which $\mathrm{HCV}$ infection may favor type 2 diabetes. $\mathrm{HCV}$ infection is thought to induce insulin resistance through multiple mechanisms, involving both the liver and peripheral tissues. ${ }^{17,18}$ Some of these mechanisms lead to an increased production of proinflammatory cytokines (such as TNF alpha and interleukin 6), ${ }^{19}$ others result in the induction of liver steatosis, which is more prevalent in patients infected with $\mathrm{HCV}$ genotype $3 .{ }^{20}$ In this study, we were unable to detect an association between a specific HCV genotype, the entity of $\mathrm{HCV}$ replication, and type 2 diabetes. This finding may have been limited by the dispersion of the different $\mathrm{HCV}$ genotypes in the cohort and the proportion of missing values which may have reduced the power to detect an association. With these limitations in mind, our observations may suggest that the presence of $\mathrm{HCV}$ replication and not its entity or type is associated with diabetes, indicating an indirect pathogenetic role for $\mathrm{HCV}$.

Other factors associated with type 2 diabetes, male sex, older age, higher baseline BMI, glucose and triglycerides, and hypertension are consistent with those found in other cohorts of HIV-infected and uninfected individuals. ${ }^{21}$ Interestingly, we also found that regimens containing d-drugs were associated with a higher risk of diabetes, consistent with their higher metabolic impact. Similarly, a higher incidence was observed for the association of NRTI with unboosted PI, probably representing older regimens with PI showing a deeper impact on insulin resistance.

Our findings have a very strong practical implication. Indeed, HCV eradication, a goal which is now obtainable in the majority of HCV/HIV co-infected individuals, may result in an additional clinical benefit in this population. We found a $73 \%(95 \%$ CI: $8 \%$ to $178 \%)$ increase in incidence of diabetes in individuals with active HCV replication. Given the overall incidence in our study population, this translates in an incidence of approximately 1.5 per 100 PY of type 2 diabetes attributable to active HCV replication. Given the chronicity of type 2 diabetes and its clinical consequences and assuming that the majority of these cases could be averted by $\mathrm{HCV}$ eradication, $\mathrm{HCV}$ treatment in this population may result in a relevant benefit in terms of both patients and public health, not only because of the prevention of liver-related morbidity and mortality.

Another goal of the current study was to explore the association of latent CMV infection with type 2 diabetes. We found no association of positive CMV IgG serostatus neither with incident nor with prevalent type 2 diabetes. This is the first analysis of this kind in the HIV-infected population and its results are in contrast with some observation in the elderly HIV-uninfected population. ${ }^{14}$ Although CMV-positive serostatus has been associated with increased immune activation in $\mathrm{HIV},{ }^{13}$ the absence of any correlation with type 2 diabetes, in contrast to the observed association with active $\mathrm{HCV}$ replication, suggests that distinct immune-inflammatory mechanisms are triggered by these 2 very different chronic viral infections. However, because we could not analyze the plasma CMV DNA status, our observation does not exclude the role of active CMV replication in determining the risk of diabetes. 
TABLE 2. Predictors of Incident Type 2 Diabetes Using a Poisson Regression Analysis

\begin{tabular}{|c|c|c|c|c|}
\hline \multirow[b]{2}{*}{ Variable } & \multicolumn{2}{|c|}{ Univariable Analysis } & \multicolumn{2}{|c|}{ Multivariable Analysis } \\
\hline & RR $(95 \%$ CI $)$ & $P$ & ARR $(95 \%$ CI) & $P$ \\
\hline Male gender vs female & $1.72(1.15$ to 2.57$)$ & 0.009 & $1.73(1.41$ to 2.12$)$ & $<0.001$ \\
\hline Age (per 10 yrs increase) & 2.05 (1.77 to 2.38$)$ & $<0.001$ & $1.06(1.04$ to 1.08$)$ & $<0.001$ \\
\hline \multicolumn{5}{|l|}{ BMI at baseline, $\mathrm{kg} / \mathrm{m}^{2}$} \\
\hline$<18.5$ & 2.35 (0.58 to 9.60$)$ & 0.234 & $0.26(0.04$ to 1.93$)$ & 0.189 \\
\hline$\geq 30$ & $13.20(3.08$ to 56.68$)$ & 0.001 & $6.47(3.49$ to 12.01$)$ & $<0.001$ \\
\hline \multicolumn{5}{|l|}{ Blood glucose at baseline, $\mathrm{mg} / \mathrm{dL}$} \\
\hline$<125$ & 1.00 & & 1.00 & \\
\hline$>125$ & 28.64 (15.72 to 52.17$)$ & $<0.001$ & $5.17(1.95$ to 13.71$)$ & 0.001 \\
\hline AST at baseline (per $50 \mathrm{U} / \mathrm{L}$ higher) & $1.00(1.00$ to 1.00$)$ & 0.071 & $1.08(1.00$ to 1.17$)$ & 0.057 \\
\hline Current triglycerides (per $100 \mathrm{mg} / \mathrm{dL}$ higher) & $1.00(1.00$ to 1.00$)$ & $<0.001$ & $1.05(1.12$ to 4.50$)$ & $<0.001$ \\
\hline $350+$ & $0.53(0.36$ to 0.77$)$ & 0.001 & $0.67(0.39$ to 1.14$)$ & 0.138 \\
\hline \multicolumn{5}{|l|}{$\mathrm{HCV}$ infection status at baseline } \\
\hline $\mathrm{HCV} \mathrm{Ab-}$ & 1.00 & & 1.00 & \\
\hline $\mathrm{HCV} \mathrm{Ab}+/ \mathrm{HCV}$ RNA- & $0.17(0.02$ to 1.25$)$ & 0.082 & $0.28(0.04$ to 2.02$)$ & 0.206 \\
\hline $\mathrm{HCV} \mathrm{Ab}+\mathrm{HCV}$ RNA+ & $1.25(0.85$ to 1.85$)$ & 0.250 & $1.73(1.08$ to 2.78$)$ & 0.023 \\
\hline $\mathrm{HCV} \mathrm{Ab+/HCV} \mathrm{RNA} \mathrm{nd}$ & $0.70(80.36$ to 1.35$)$ & 0.285 & $0.71(0.30$ to 1.69$)$ & 0.439 \\
\hline $\mathrm{HCV} \mathrm{Ab}$ nd & $0.82(0.38$ to 1.78$)$ & 0.622 & $0.86(0.34$ to 2.17$)$ & 0.752 \\
\hline HCV genotype 2 vs 1 & $1.53(0.20$ to 11.88$)$ & 0.683 & & \\
\hline 3 vs 1 & $1.64(0.73$ to 3.66$)$ & 0.227 & & \\
\hline 4 vs 1 & $1.81(0.63$ to 5.21$)$ & 0.271 & & \\
\hline HCV RNA (per $1 \log$ IU/mL higher) & $1.10(0.91$ to 1.32$)$ & 0.322 & & \\
\hline Other & $1.72(0.75$ to 3.91$)$ & 0.198 & $1.54(0.61$ to 3.87$)$ & 0.361 \\
\hline \multicolumn{5}{|l|}{ Current NRTI combination } \\
\hline tenofovir + emtricitabine & 1.00 & & 1.00 & \\
\hline tenofovir + lamivudine & $0.26(0.03$ to 1.88$)$ & 0.181 & 0.27 (0.04 to 2.04$)$ & 0.205 \\
\hline abacavir + lamivudine & $0.97(0.40$ to 2.37$)$ & 0.950 & $1.16(0.47$ to 2.90$)$ & 0.749 \\
\hline zidovudine + lamivudine & $1.24(0.73$ to 2.12$)$ & 0.423 & $1.07(0.57$ to 2.02$)$ & 0.835 \\
\hline stavudine + lamivudine & $2.53(1.39$ to 4.59$)$ & 0.002 & $2.52(1.22$ to 5.20$)$ & 0.013 \\
\hline stavudine + didanosine & $1.18(0.45$ to 3.07$)$ & 0.741 & $1.09(0.39$ to 3.06$)$ & 0.872 \\
\hline
\end{tabular}

Variables assayed in the multivariable model include only those associated with $P<0.1$ at univariable analysis plus Cytomegalovirus IgG status.

ARR, adjusted relative risk; BMI, body mass index; CDC, centers for disease control; NRTI, nucleoside reverse transcriptase inhibitors; NNRTI, non-nucleoside reverse transcriptase inhibitors; PI, protease inhibitors; RR, relative risk.

The results of this study should be interpreted with caution given its retrospective nature. However, in the ICONA cohort, this limitation is only partial, given the fact that patients are enrolled and followed prospectively and that the diagnosis of clinical events, including diabetes, is validated by an external monitor using standardized criteria.
In conclusion, in this large observational study, we found a significant association of active HCV replication with incident and prevalent type 2 diabetes. This result is consistent with previous observations in the HCV monoinfected population and with the hypothesized mechanism by which HCV may induce liver steatosis and insulin resistance. 
TABLE 3. Factors Associated With Prevalent Type 2 Diabetes Using Logistic Regression

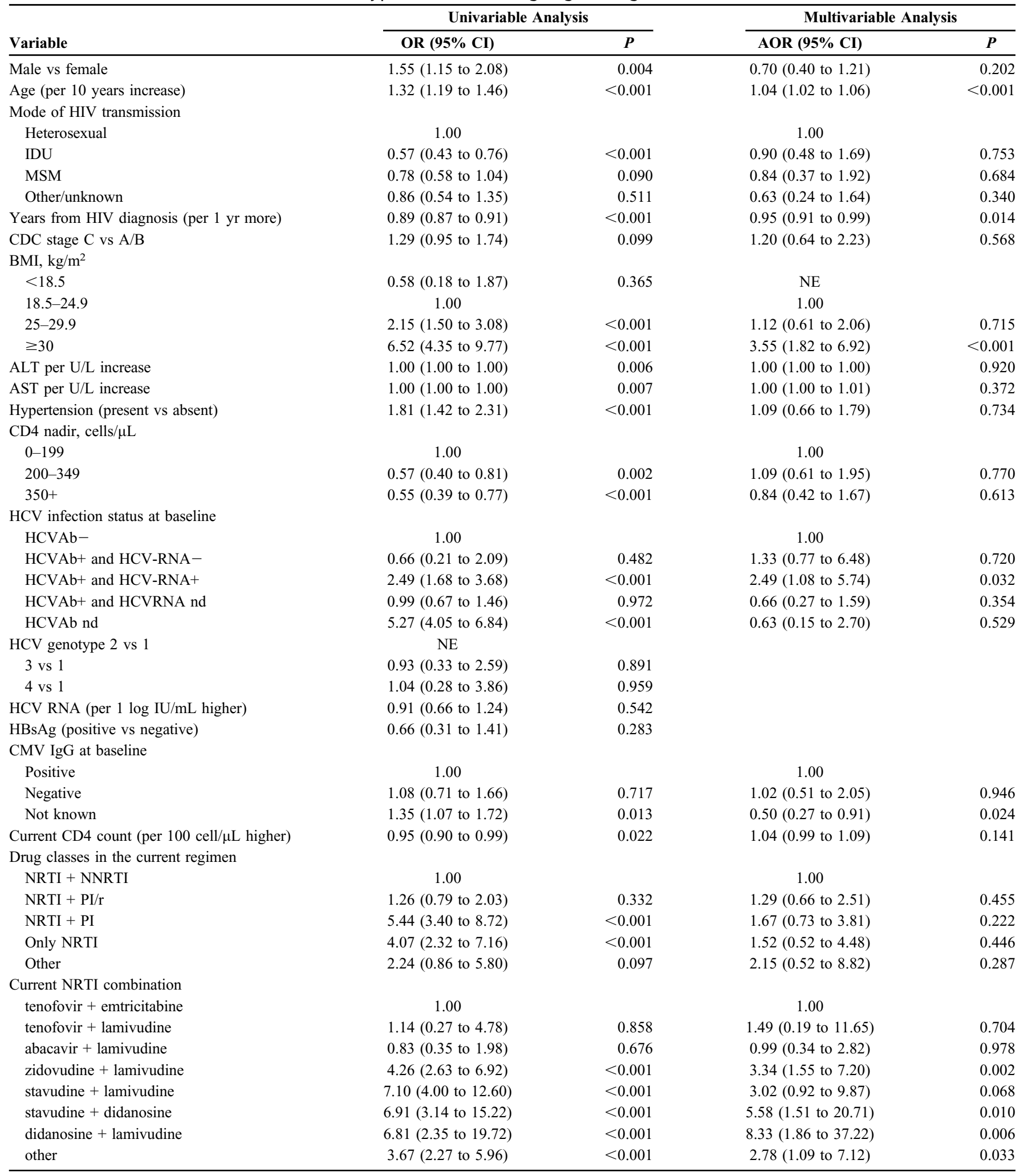

Variables assayed in the multivariable model included only those associated with $P<0.1$ at univariable analysis.

AOR, adjusted odds ratio; BMI, body mass index; CDC, centers for disease control; NE, not estimable; NRTI, nucleoside reverse transcriptase inhibitors; NNRTI, non-nucleoside reverse transcriptase inhibitors; OR, odds ratio; PI, protease inhibitors. 
Future studies should aim to determine whether $\mathrm{HCV}$ eradication with antiviral therapy may be able to revert this increased risk.

\section{ACKNOWLEDGMENTS}

ICONA Foundation cohort study: BOARD OF DIRECTORS: A.d'A.M. (Vice-President), M. Andreoni, G. Angarano, A.A., F.C., R. Cauda, G. Di Perri, M. Galli, R. Iardino, G. Ippolito, A. Lazzarin, C. F. Perno, F. von Schloesser, P. Viale. SCIENTIFIC SECRETARY: A.d'A.M., A.A., A.C., F. Ceccherini-Silberstein, A. Cozzi-Lepri, E. Girardi, S. Lo Caputo, C. Mussini, M.P. STEERING COMMITTEE: M. Andreoni, A. Ammassari, A.A., C. Balotta, A. Bandera, P. Bonfanti, S. Bonora, M. Borderi, A. Calcagno, L. Calza, M. R. Capobianchi, A.C., F. Ceccherini-Silberstein, A. Cingolani, P. Cinque, A. CozziLepri, A.d'A.M., A.D.L., A. Di Biagio, E. Girardi, N.G., A. Gori, G.G., G. Lapadula, M.L., S. Lo Caputo, G. Madeddu, F.M., G. Marchetti, S. Marcotullio, L. Monno, C. Mussini, S. Nozza, M.P., E. Quiros Roldan, R. Rossotti, S. Rusconi, M. M. Santoro, A. Saracino, M. Zaccarelli. STATISTICAL AND MONITORING TEAM: A. Cozzi-Lepri, I. Fanti, L. Galli, P.L., A. Rodano, M. Shanyinde, A. Tavelli. BIOLOGICAL BANK INMI: F. Carletti, S. Carrara, A. Di Caro, S. Graziano, F. Petrone, G. Prota, S. Quartu, S. Truffa. PARTICIPATING PHYSICIANS AND CENTERS: Italy A. Giacometti, A. Costantini, C. Valeriani (Ancona); G. Angarano, L. Monno, C. Santoro (Bari); F.M., C. Suardi (Bergamo); P. Viale, V. Donati, G. Verucchi (Bologna); F. C., E. Quiros Roldan, C. Minardi (Brescia); T. Quirino, C. Abeli (Busto Arsizio); P. E. Manconi, P. Piano (Cagliari); B. Cacopardo, B. Celesia (Catania); J. Vecchiet, K. Falasca (Chieti); L. Sighinolfi, D. Segala (Ferrara); F. Mazzotta, F. Vichi (Firenze); G. Cassola, C. Viscoli, A. Alessandrini, N. Bobbio, G. Mazzarello (Genova); C.M., V. Belvisi (Latina); P. Bonfanti, I. Caramma (Lecco); A. Chiodera, A. P. Castelli (Macerata); M. Galli, A. Lazzarin, G. Rizzardini, M.P., A.d'A.M., A. L. Ridolfo, R. Piolini, A. C., S. Salpietro, L. Carenzi, M. C. Moioli, C. Tincati, G. Marchetti (Milano); C. Mussini, C. Puzzolante (Modena); A. Gori, G. Lapadula (Monza); N. Abrescia, A. Chirianni, G. Borgia, F. Di Martino, L. Maddaloni, I. Gentile, R. Orlando (Napoli); F. Baldelli, D. Francisci (Perugia); G. Parruti, T. Ursini (Pescara); G. Magnani, M. A. Ursitti (Reggio Emilia); R. Cauda, M. Andreoni, A.A., V. Vullo, A. Cristaudo, A. Cingolani, G. Baldin, S. Cicalini, L. Gallo, E. Nicastri, R. Acinapura, M. Capozzi, R. Libertone, S. Savinelli, A. Latini, G. Iaiani, L. Fontanelli Sulekova (Roma); M. Cecchetto, F. Viviani (Rovigo); M. S. Mura, G. Madeddu (Sassari); A.D.L., B. Rossetti (Siena); P. Caramello, G. Di Perri, G. C. Orofino, S. Bonora, M. Sciandra (Torino); M. Bassetti, A. Londero (Udine); G. Pellizzer, V. Manfrin (Vicenza).

\section{REFERENCES}

1. Samji H, Cescon A, Hogg RS, et al. Closing the gap: increases in life expectancy among treated HIV-positive individuals in the United States and Canada. PLoS One. 2013;8:e81355.

2. Serrano-Villar S, Gutiérrez F, Miralles C, et al. Human immunodeficiency virus as a chronic disease: evaluation and management of nonacquired immune deficiency syndrome-defining conditions. Open Forum Infect Dis. 2016;3:ofw097.

3. Ingiliz P, Rockstroh JK. Natural history of liver disease and effect of hepatitis C virus on HIV disease progression. Curr Opin HIV AIDS. 2015; 10:303-308.

4. Butt AA, McGinnis K, Rodriguez-Barradas MC, et al; Veterans Aging Cohort Study. HIV infection and the risk of diabetes mellitus. AIDS. 2009;23:1227-1234.

5. Data Collection on Adverse Events of Anti-HIV drugs (D:A:D) Study Group, Smith C, Sabin CA, et al. Factors associated with specific causes of death amongst HIV-positive individuals in the D:A:D Study. AIDS 2010;24:1537-1548.

6. De Wit S, Sabin CA, Weber R, et al. Incidence and risk factors for newonset diabetes in HIV-infected patients: the data collection on Adverse events of Anti-HIV drugs (D:A:D) study. Diabetes Care. 2008;31:1224 1229 .

7. Brown TT, Cole SR, Li X, et al. Antiretroviral therapy and the prevalence and incidence of diabetes mellitus in the multicenter AIDS cohort study. Arch Intern Med. 2005;165:1179-1184.

8. Capeau J, Bouteloup V, Katlama C, et al. Ten-year diabetes incidence in 1046 HIV-infected patients started on a combination antiretroviral treatment. AIDS. 2012;26:303-314.

9. Basseri B, Yamini D, Chee G, et al. Comorbidities associated with the increasing burden of hepatitis C infection. Liver Int. 2010;30:1012-1018.

10. White DL, Ratziu V, El-Serag HB. Hepatitis C infection and risk of diabetes: a systematic review and meta-analysis. $J$ Hepatol. 2008;49: 831-844.

11. Ledergerber B, Furrer H, Rickenbach M, et al. Factors associated with the incidence of type 2 diabetes mellitus in HIV-infected participants in the Swiss HIV Cohort Study. Clin Infect Dis. 2007;45:111-119.

12. Yoon C, Gulick RM, Hoover DR, et al. Case-control study of diabetes mellitus in HIV-infected patients. J Acquir Immune Defic Syndr. 2004; 37:1464-1469.

13. Lichtner M, Cicconi P, Vita S, et al. Cytomegalovirus coinfection is associated with an increased risk of severe non-AIDS-defining events in a large cohort of HIV-infected patients. J Infect Dis. 2015;211:178-186.

14. Chen S, de Craen AJ, Raz Y, et al. Cytomegalovirus seropositivity is associated with glucose regulation in the oldest old. Results from the Leiden 85-plus Study. Immun Ageing. 2012;9:18.

15. d'Arminio Monforte A, Cozzi-Lepri A, Rezza G, et al. Insights into the reasons for discontinuation of the first highly active antiretroviral therapy (HAART) regimen in a cohort of antiretroviral naive patients. I.CO.N.A Study Group. Italian Cohort of Antiretroviral-Naive Patients. AIDS 2000;14:499-507.

16. Sulkowski MS. HCV-HIV co-infected patients: no longer a "special" population? Liver Int. 2016;36(suppl 1):43-46.

17. Kralj D. Hepatitis C virus, insulin resistance and steatosis. J Clin Transl Hepatol. 2016;4:66-75.

18. Milner KL. Chronic hepatitis $\mathrm{C}$ is associated with peripheral rather than hepatic insulin resistance. Gastroenterology. 2010;138:932-941.

19. Lecube A. Proinflammatory cytokines, insulin resistance, and insulin secretion in chronic hepatitis C patients: a case control study. Diabetes Care. 2006;29:1096-1101.

20. Pazienza V. Hepatitis C virus core protein genotype 3 a increases SOCS7expression through PPAR-(gamma) in Huh-7 cells. J Gen Virol. 2010; 91:1678-1686.

21. Petoumenos K, Worm SW, Fontas E, et al; D:A:D Study Group. Predicting the short-term risk of diabetes in HIV-positive patients: the data collection on Adverse events of Anti-HIV drugs (D:A:D) study. J Int AIDS Soc. 2012;15:17426. 